\title{
Geographic and Temporal Heterogeneity in Public Prescription Pharmaceutical Expenditures in Spain
}

\author{
Jørgen Lauridsen, Mickael Bech, Fernando López, and Mariluz Maté Sánchez
}

\begin{abstract}
A panel of aggregate data for 50 provinces is used to analyze Spain's per capita public pharmaceutical expenditures. In contrast to previous practice, our approach permits the analysis of the effects determinants on pharmaceutical expenditure to be heterogeneous across years and provinces. Considerable parametric heterogeneity over time as well as across provinces is found, even after controlling for residual temporal heterogeneity and interdependence as well as residual spatial spillovers. This underlines the need for using disaggregate spatial data when attempting to model macroeconomic behavior.
\end{abstract}

Key Words: pharmaceutical expenditure; spatial expansion; varying coefficients; Seemingly Unrelated Regression; spatial autocorrelation

JEL Classifications: I11, L65, R15, C21, C23

\section{INTRODUCTION}

During the last decade, public pharmaceutical expenditures in Spain have grown faster than total public health care spending (Darbá 2003a; Darbá, 2003b). Thus, public pharmaceutical expenditure makes up an increasing share of total public health care spending. Pharmaceutical expenditure made up 16.8 percent in 1991 and had by 2002 increased to make up 23 percent of Spain's total health care spending (Lopez-Casanovas et al., 2005). This growth is found not only in Spain, but is a general feature of the European Union (Ess et al., 2003). Nonetheless, Spanish pharmaceutical expenditures as a share of public health care spending exceed the European Union's, raising questions about the causes of this rapid growth (Lopez-Casanovas, 2005).

The regulation of the pharmaceutical market in Spain is shared between national regulatory bodies and the regional authorities. There are notable differences in health resources supply and health care expenditure across regions (Lopez-Casanovas et al., 2005). There also is evidence of regional variation in prescription rates and expenditure per prescription resulting in regional heterogeneity in pharmaceutical expenditure and in the pharmaceutical expenditure as a share of the total regional health care expenditure (Costa-Font and Puig-Junoy, 2004).

Studies on pharmaceutical expenditure from the regional perspective are scant, though it is possible to find a few works dealing with the analysis of regional health care expenditure (Lopez-Casasnovas and Saez, 2001; Kitchener et al., 2003; Levaggi and Zanola, 2003; Moscone and Knapp, 2005). Despite an ample body of evidence in the literature on variations in the use of procedures at the local level (Wennberg and Gittelsohn, 1973; Ham, 1988; Folland et al., 2003; Joines et al., 2003; Westert et al., 2004), few studies have examined the geographical variability in the consumption of pharmaceuticals (Metge et al., 1999; Dubois et al., 2002; Morgan, 2005). The causes of variation discussed in the literature include regional differences in the prevalence

\footnotetext{
${ }^{*}$ Lauridsen and Bech are affiliated with the Institute of Public Health, Health Economics, University of Southern Denmark, Odense, Denmark. López and Maté Sánchez are affiliated with the Department of Quantitative and Computational Methods, Polytechnical University of Cartagena, Cartagena, Spain.

Contact author: Jørgen Lauridsen, Campusvej 55, DK-5230 Odense M, DENMARK. E-mail jtl@sam.sdu.dk.
}

(C) Southern Regional Science Association 2010. 
of diseases, opinions regarding the effectiveness of surgery, medical practice style, the supply of health resource, and patient preferences.

Only a few studies of small-area variation have considered spatial variation in medical practice. One studied spatial disparities in hospital discharges (measured by coefficients of variation) and found these disparities to be relatively unchanged during the 1980s and 1990s (Westert et al., 2004). Another study by Joines et al. (2003) found that hospitalization rates for lower back problems varied significantly across counties of North Carolina. They further found that counties with similar rates were geographically clustered and concluded that spatial effects are important and should be considered in small-area studies. A third study by Moscone and Knapp (2005) explored the spatial patterns of mental health expenditure and established, similar to Joines et al. (2003), the importance of controlling for spatial spillovers. This study found a positive significant spatial effect suggesting that adjacent local authorities mimic the behavior of their neighbors and tend to have similar mental health expenditure.

The present study focuses on provincial variations in the determinants of public pharmaceutical expenditure in Spain and aims to contribute to the literature on small-area variation in the determinants of health care expenditures. Specifically, we suggest integrating three modeling features. First, parametric heterogeneity is captured by specifying a model that includes a time trend and geographical coordinates of the provinces. Second, in order to obtain efficient results, a seemingly unrelated regression (SUR) framework is applied to capture

intertemporal residual correlation and time-varying residual variances. Finally, residual spatial spillovers are controlled for by specifying spatially autocorrelated (SAC) residuals. We conclude that the effects of determinants vary substantially across time as well as across provinces, and that potentially misleading conclusions regarding the effects of key determinants like GDP and health system characteristics can occur if simpler specifications are applied.

\section{THE SPANISH PHARMACEUTICAL MARKET}

In Spain, the prices of publicly financed pharmaceuticals are fully or partially controlled, and the real price of medicines has not risen much in the last decade. Nevertheless, this does not preclude new products from entering the market at prices that are higher than those of existing ones. Several studies have shown that the replacement of older drugs by newer, more expensive, drugs is the single most important cause of increases in pharmaceutical expenditures (Dubois et al., 2000; Gerdtham and Lundin, 2004; Morgan, 2005); real prices of existing drugs are actually decreasing. The second most important cause is that larger quantities are consumed because of increases in the intensity of medication, defined in terms of daily dose per patient. Similar results are found for Spain in analyses of nationwide increases in pharmaceutical expenditures (Rovira et al., 2001; Darbá, 2003b).

The Spanish national health system is decentralized. The regulation of the pharmaceutical market is shared between national regulatory bodies and the regional authorities - called Autonomous Communities (AC). Most of the key regulatory bodies, however, are run centrally at the national level. This reduces diversity and helps maintain overall cost control (Costa-Font and Puig-Junoy, 2004). See Figure 1 for a map of provinces by AC.

Even though cost containment has been a major priority for publicly financed pharmaceuticals, it has not significantly curbed public spending (Darbá, 2003a; Darbá, 2003b; Costa-Font and Puig-Junoy, 2004). Average prices for pharmaceuticals in Spain are relatively low. Spain, of course, does consume some older (many generic) drugs that are priced significantly below the EU average (Puig-Junoy, 2004). In 2000, however, the market share for 


\section{FIGURE 1. Provinces with Autonomous Communities Shown}

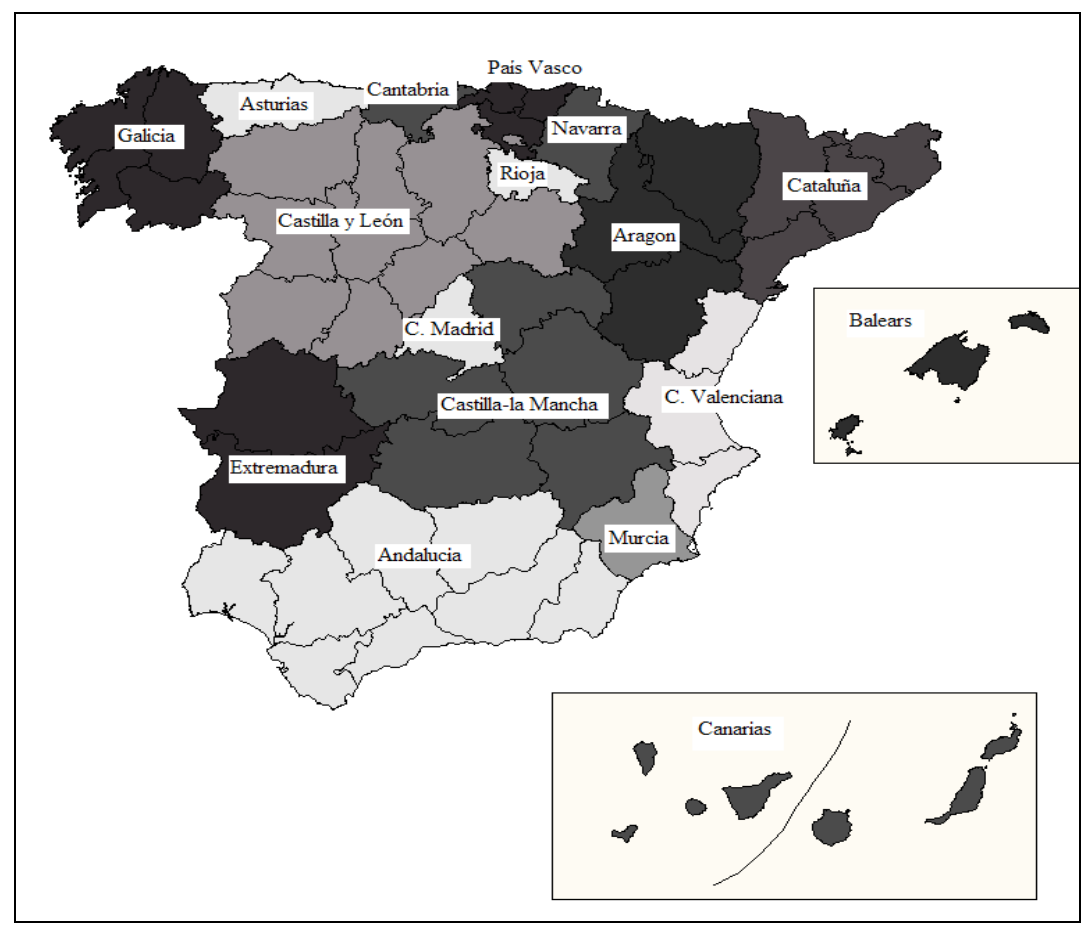

generic drugs in Spain was surprisingly lower than that in the EU overall. But the share has been rising. It accounted for 3 percent of the Spanish drug sales in 2000 and increased to 6.4 percent by 2003 (Costa-Font and Puig-Junoy, 2004). Moreover, there seems to be significant regional heterogeneity in the use of generics in Spain (Costa-Font and Puig-Junoy, 2004). New drugs own a disproportionate share of the pharmaceutical market in Spain (Darbá, 2003a; Darbá, 2003b; Costa-Font and Puig-Junoy, 2004). Combined, this suggests that in Spain newer drugs are priced modestly below the EU average.

Various cost containment policies such as negative lists of excluded drugs, regulation of profits, repayments from pharmaceutical companies, reference pricing system and promotion of generic drugs have had little effect on the overall increase in pharmaceutical expenditure. Some of these policies are under the devolved responsibility of the 17 regional health systems. The ACs gradually became significant actors in pharmaceutical policy, starting in the early 1980s and fully formed with the completion of the devolution process in 2002.

Funding is mainly centrally collected and distributed to the ACs. Until 2001, regional health care financing was decided in a separate negotiation between the Minister of Health and the corresponding Regional Ministers in the 17 ACs, mainly as block grants following the lines of an unadjusted capitation formula (Lopez-Casasnovas, Costa-Font, and Planas, 2005). Since 2002, health care expenditures have been allocated as part of the general financing using a capitation formula with some demographic adjustments. Health care expenditures account for around 40 percent of the ACs' total funding. The ACs can change health care funding through their own tax structures, but various forms of central funds are applied to maintain interregional equity. Some interregional inequalities remain in health expenditure per capita, but the coefficient of variation in regional health care expenditure per capita is one of the lowest among 
health care systems for which territorial health care expenditure may be identified (LopezCasanovas and Saez, 2001).

There seem to be significant regional differences in hospital specialization, physician density and available medical technology. It has been suggested that this diversity can be explained partly by differences in a particular region's GDP contributions and demographic compositions (Lopez-Casasnovas, Costa-Font, and Planas, 2005). Interestingly, regional inequality in health expenditure is not correlated with inequality in health outcomes (LopezCasasnovas, Costa-Font, and Planas, 2005). There is, however, evidence of significant regional variation in prescription rates and expenditure per prescription resulting in significant regional heterogeneity in pharmaceutical expenditure as a share of the total regional health care expenditure (Costa-Font and Puig-Junoy 2004).

\section{METHODOLOGY}

Assuming a cross-section of $N=50$ provinces, a basic homoskedastic linear regression model can be written as:

$$
y_{t}=X_{t} \beta+v_{t}, \quad v_{t} \sim N\left(0, \sigma^{2} I\right),
$$

where $X_{t}$ is an $N$ by $K$ dimensional matrix of explanatory variables, $y_{t}$ is an $N$ dimensional vector of endogenous observations, $\beta$ is a $K$ dimensional vector of coefficients, and $v_{t}$ is a residual with variance $\sigma^{2}$.

A restrictive assumption of the model expressed in equation (1) is that $\beta$ is constant over time and across provinces. Actually, this is a precondition for $v_{t}$ to remain homoskedastic. To allow the $\beta$ coefficients to vary across time and provinces, we apply expansions (Jones and Casetti, 1992; Casetti, 1997). The effect of the $k^{\text {th }}$ regressor $(k=0, . ., K$, with the convention that $\beta_{0}$ is the constant term, i.e., $X_{0}=1$ ) is specified as:

$$
\beta_{k}=\alpha_{0 k}+\alpha_{T k} T+\alpha_{H k} H+\alpha_{H^{2} k} H^{2}+\alpha_{V k} V+\alpha_{V^{2} k} V^{2}+\alpha_{H V k} H V,
$$

where $\alpha_{j k}\left(j=T, H, H^{2}, V, V^{2}, H V\right)$ are coefficients, $\mathrm{T}$ is a time trend, and $H$ and $V$ are the horizontal (west to east) and vertical (south to north) coordinates of the geographical midpoints of the regions respectively, The square terms $H^{2}$ and $V^{2}$ together with the interaction term $H V$ is inserted to allow for non-linear and diagonal dispersion of the $\beta$ coefficients. Inserting (2) in (1) gives the expanded specification:

$$
\begin{aligned}
& Y_{t}=\sum_{k=0}^{K}\left\{\alpha_{0 k} X_{t k}+\alpha_{T k}\left(T X_{t k}\right)\right. \\
& \left.+\alpha_{H k}\left(H X_{t k}\right)+\alpha_{H^{2} k}\left(H^{2} X_{t k}\right)+\alpha_{V k}\left(V X_{t k}\right)+\alpha_{V^{2} k}\left(V^{2} X_{t k}\right)+\alpha_{H V k}\left(H V X_{t k}\right)\right\}+v_{t} .
\end{aligned}
$$

Operationally, expanded specification (3) can be estimated by applying multiplicative interaction terms between $X_{k}$ and the $T, H, V$, and $H V$ variables. Next, the $\beta_{k}$ coefficients for each province by each time period, say $\beta_{\text {kit }}$, can be calculated from (2) together with their standard errors, as the $\beta$ parameters are simple linear functions of the $\alpha$ parameters. Finally, 
the average for each time period and the average for each region are readily obtained to serve illustrative and interpretational purposes.

Furthermore, one should be aware of the potential sensitivity of the $\alpha_{j k}$ parameters and their $t$ values to collinearity caused by the inclusion of the interaction terms in (3). However, their linear combinations (i.e., the $\beta_{\text {kit }}$ parameters) and their $t$ values do not share this sensitivity. Thus, interpretation of the results should be based on the $\beta_{k i t}$ parameters rather than the $\alpha_{j k}$ parameters.

In order to obtain efficient estimation results, the structure of the residuals needs consideration. First, to account for residual spatial spillovers, the spatially autocorrelated (SAC) specification (Anselin, 1988) is applied to the residual of (3), that is:

$$
v_{t}=\lambda W v_{t}+\varepsilon_{t},
$$

where $\lambda$ is an autocorrelation parameter and $W$ an $N \times N$ contiguity matrix defined by letting $w_{i j}$ equal $1 / n_{i}$ if provinces $i$ and $j$ are neighbors $(i \neq j)$ and 0 otherwise, as $n_{i}$ is the number of neighbors to province $i$. Intuitively, the product $W v_{t}$ defines a variable for each province that is the average $v_{t}$ of neighboring provinces. Next, when applying pooled data for $T$ periods, the residuals are temporally correlated and the variances for the cross sections fluctuate with time. Thus, between any two points in time, the residual covariance of $\varepsilon_{t}$ is specified as:

$$
E\left(\varepsilon_{t}{ }^{\prime} \varepsilon_{s}\right)=\sigma_{t s}^{2}, t, s=1, . ., T .
$$

The model defined by (3), (4), and (5) is estimated efficiently by applying the following maximum likelihood approach. We performed a grid search of the relevant values of $\lambda$ from -1 to +1 . Conditioned on each $\lambda$, a feasible generalized least squares (F-GLS) estimation (Zellner 1962) is applied to (3) using $(I-\lambda W) y_{t}$ instead of $y_{t}$ and $(I-\lambda W) X_{t}$ instead of $X_{t}$ to obtain SUR estimates of $\beta$. Finally, the set of results which maximized the log likelihood function are selected. For well-behaved data, this procedure produces results similar to those of the traditional maximum likelihood estimation. For ill-behaved data, however, traditional maximum likelihood estimation may lead to suboptimal estimates due to attainment only of local optima. While the grid search procedure is slightly more time consuming, it is less disposed to attaining local optima as opposed to the global one.

To compare alternative models, the pseudo- $R^{2}$ and the Akaike information criterion (AIC) are used. Wald tests for the expansions also are provided, i.e., for the hypotheses that $\alpha_{T}$ and/or $\left(\alpha_{H}, \alpha_{H^{2}}, \alpha_{V}, \alpha_{V^{2}}, \alpha_{H V}\right)$ equal 0 .

\section{DATA}

Data for 50 Spanish provinces were collected. These provinces correspond with the NUT-3 level of aggregation according to EUROSTAT (excluding the autonomous cities of Ceuta and Melilla). The provinces are grouped into 17 Autonomous Communities (AC). The ACs correspond with the NUT-2 level of aggregation according to EUROSTAT. They present a higher degree of heterogeneity than do the provinces. Regarding the decentralization process, 
seven of the ACs had independent responsibilities during the 1980s and 1990s, while the last 10 took on responsibility for health care regulation in 2002.

The data were collected annually from 1996 to 2003 from two sources, the National Statistical Institute (INE) and the Ministry of Health and Consumption (MSC). The dependent variable is public pharmaceutical expenditure per capita $(E X P)$. It includes expenditures on extra-hospital drugs managed by the administration, but does not take private purchases into account. To capture the influence of wealth, GDP per capita (GDP) is included as an explanatory variable. Further, to capture influences of the health care system, the number of pharmacists per 1000 inhabitants (PHARM), number of hospital beds per 1000 inhabitants (BEDS), and number of medical doctors per 1000 inhabitants (MED) are included. Finally, to capture the influence of the composition of the population, the share of population that is female $(F E M)$, foreigners (FOREIGN), people over 65 years $(O L D)$, and 0 to 4 year old children (CHILD) are included. Table 1 presents the data applied, including means and standard deviations (average over eight years).

The variables describing the population control for socio-demographic risk factors and are considered to be proxies for need, whereas GDP controls for ability to pay. The variables describing the health care system do not solely reflect supply factors but are a result of interactions between demand and supply factors. Some health system variables may be considered to be substitutes for the utilization of pharmaceuticals while others are complementary. A priori, one would expect the number of pharmacists to be complementary whereas we have no unambiguous a priori hypothesis for hospital beds and medical doctors.

\section{TABLE 1. Variables Used in the Analysis}

\begin{tabular}{|c|c|c|c|c|}
\hline Variable & Description & Source & Mean & Std. D. \\
\hline EXP & $\begin{array}{l}\text { Pharmaceutical Expenditure } \\
\text { per capita }\end{array}$ & $\begin{array}{l}\text { MSC, Institute of } \\
\text { Sanitary Information }\end{array}$ & 164.899 & 31.710 \\
\hline$G D P$ & GDP per capita & $\begin{array}{l}\text { INE, National } \\
\text { Statistical Institute }\end{array}$ & 9241.57 & 1766.14 \\
\hline PHARM & $\begin{array}{l}\text { Pharmacists per } 1000 \\
\text { inhabitants }\end{array}$ & $\begin{array}{l}\text { INE, Social Indicators, } \\
2004\end{array}$ & 1.206 & 0.225 \\
\hline$B E D S$ & $\begin{array}{l}\text { Hospital beds per } 1000 \\
\text { inhabitants }\end{array}$ & $\begin{array}{l}\text { MSC, National Hospital } \\
\text { Catalogue }\end{array}$ & 0.004 & 0.001 \\
\hline$M E D$ & $\begin{array}{l}\text { Medical doctors per } 1000 \\
\text { inhabitants }\end{array}$ & $\begin{array}{l}\text { INE, Social Indicators, } \\
2004\end{array}$ & 4.183 & 0.739 \\
\hline FEM & Share of population female & $\begin{array}{l}\text { INE,National Statistical } \\
\text { Institute }\end{array}$ & 0.506 & 0.006 \\
\hline FOREIGN & Share of population foreign & $\begin{array}{l}\text { INE, National } \\
\text { Statistical Institute }\end{array}$ & 0.018 & 0.019 \\
\hline$O L D$ & $\begin{array}{l}\text { Share of population over } 65 \\
\text { years }\end{array}$ & $\begin{array}{l}\text { INE, National } \\
\text { Statistical Institute }\end{array}$ & 0.185 & 0.042 \\
\hline CHILD & $\begin{array}{l}\text { Share of population } \\
\text { between } 0 \text { to } 4 \text { years }\end{array}$ & $\begin{array}{l}\text { INE, National } \\
\text { Statistical Institute }\end{array}$ & 0.090 & 0.016 \\
\hline
\end{tabular}


FIGURE 2. Variables by Provinces

(darker tones indicate larger magnitudes)

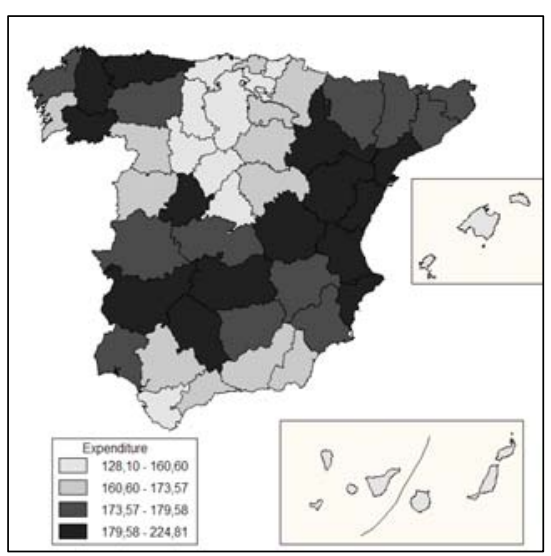

EXP

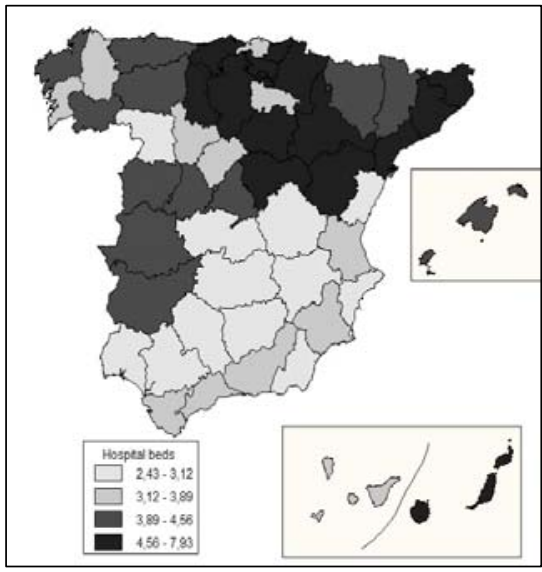

BEDS

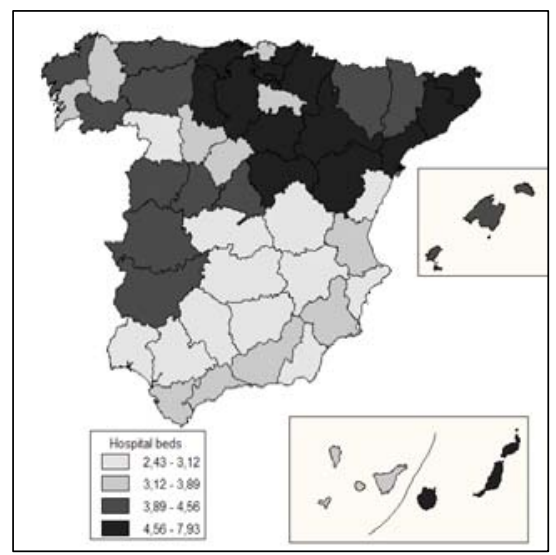

BEDS

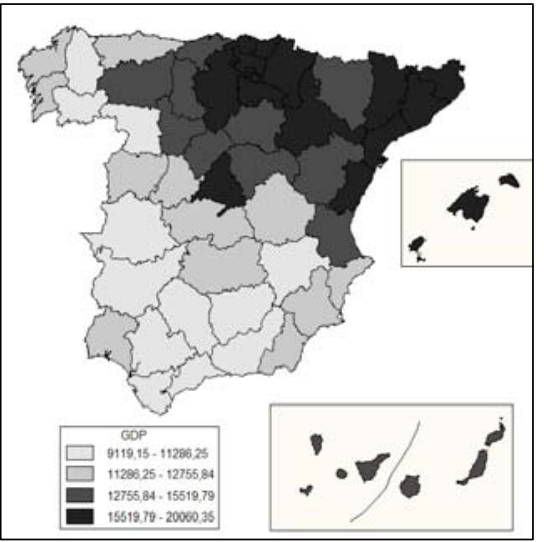

$G D P$

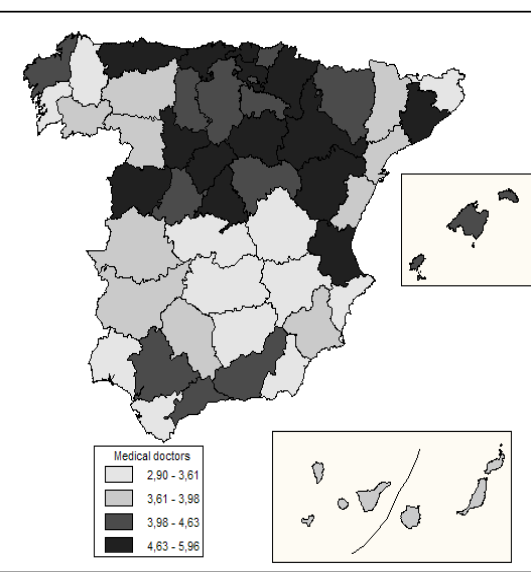

MED

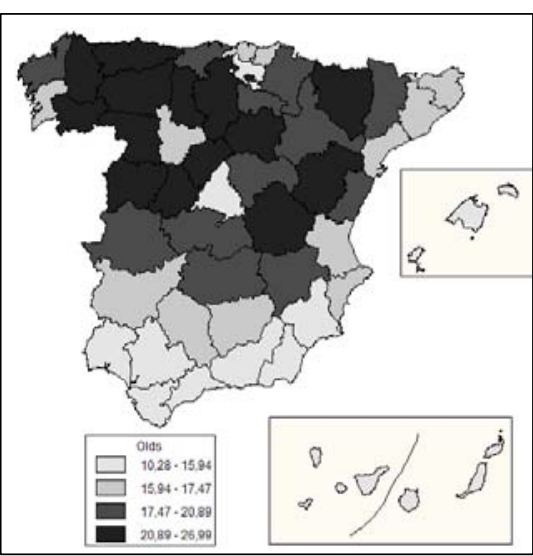

$O L D$

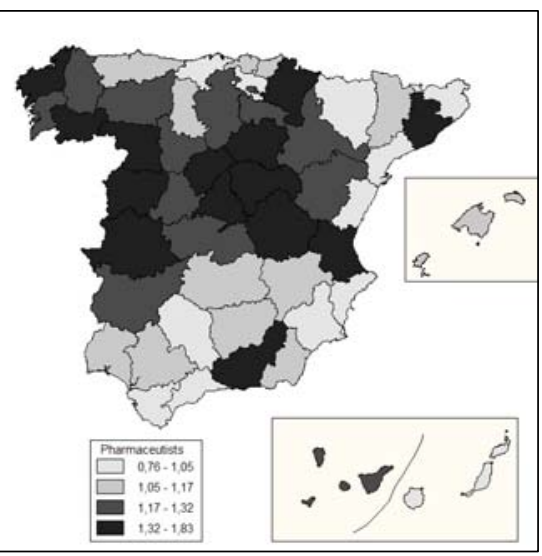

PHARM

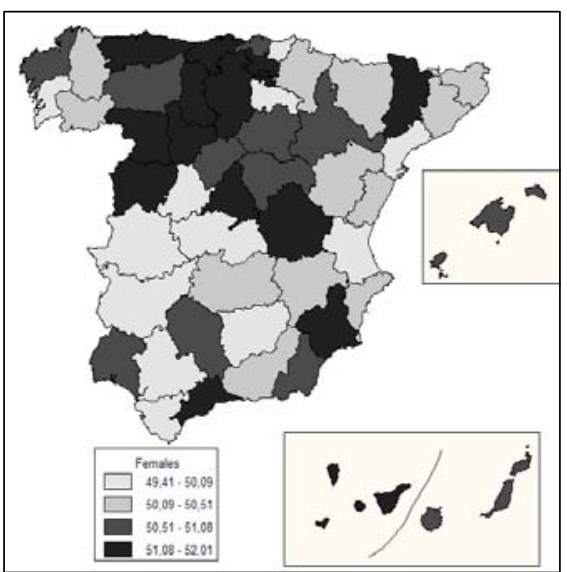

FEM

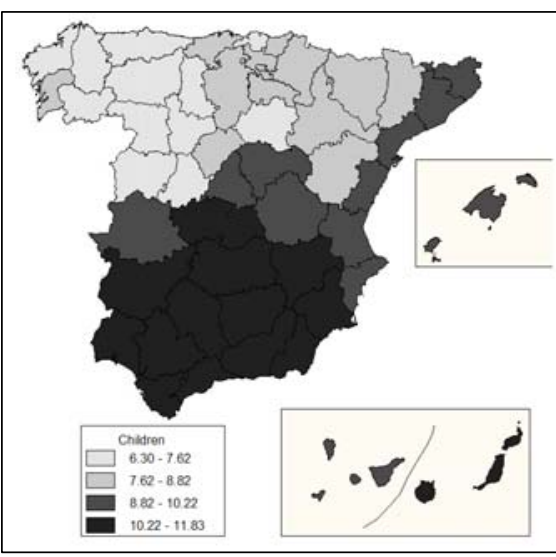

CHILD

(c) Southern Regional Science Association 2010. 
FIGURE 3. Student $t$-Values of Coefficients by Provinces (averaged over eight years)

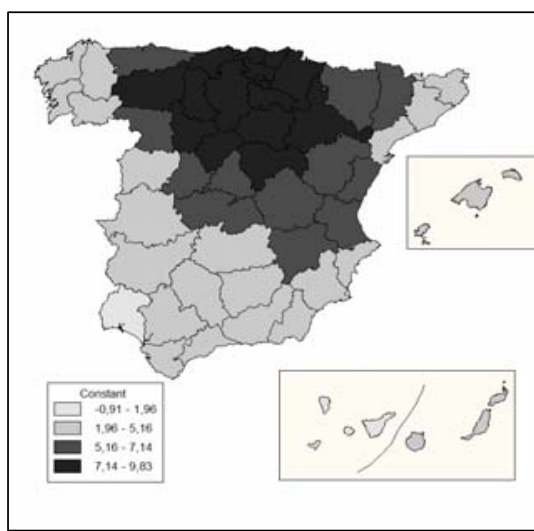

Constant

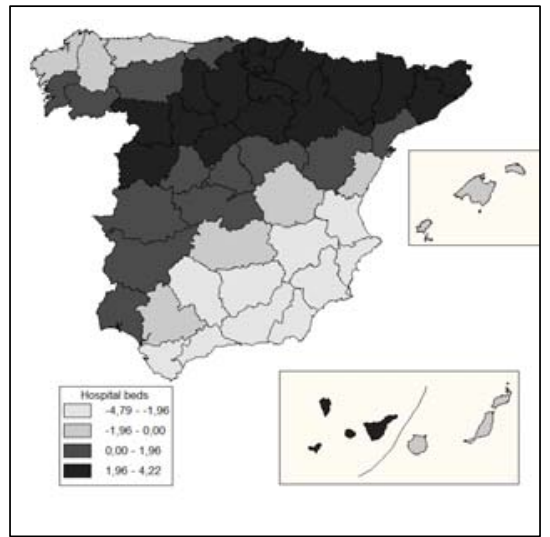

$B E D S$

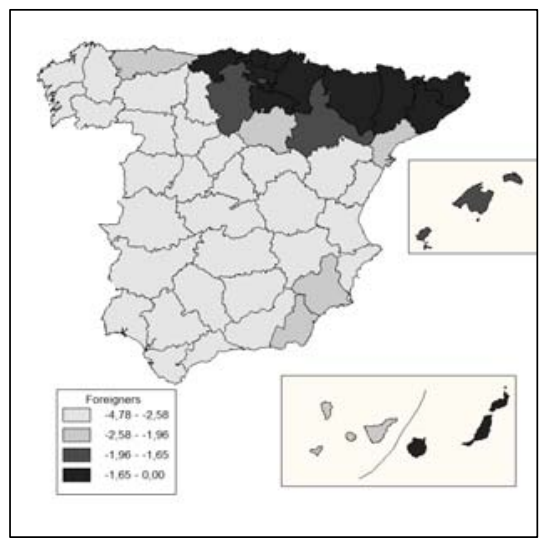

FOREIGN

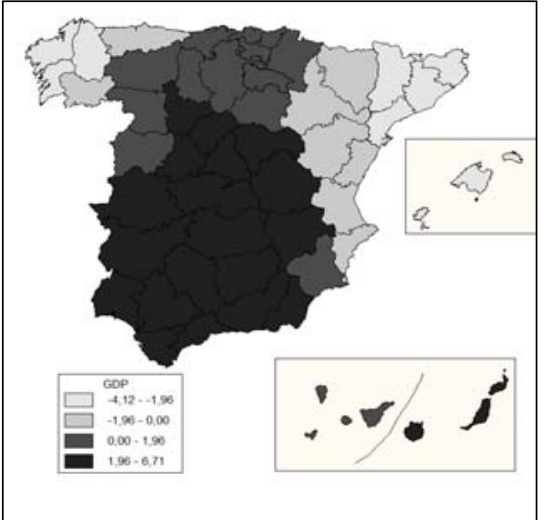

$G D P$

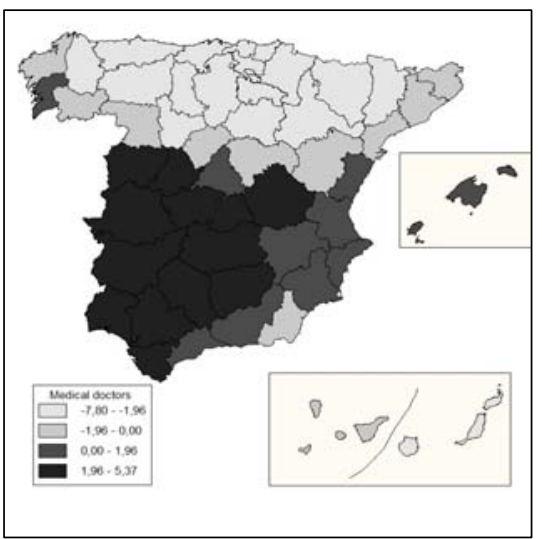

MED

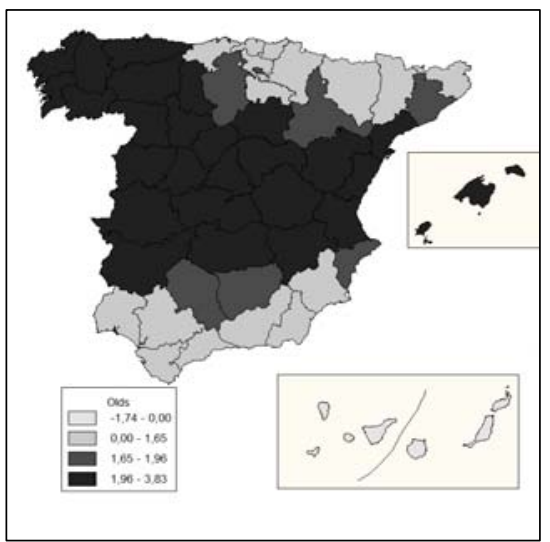

OLDS

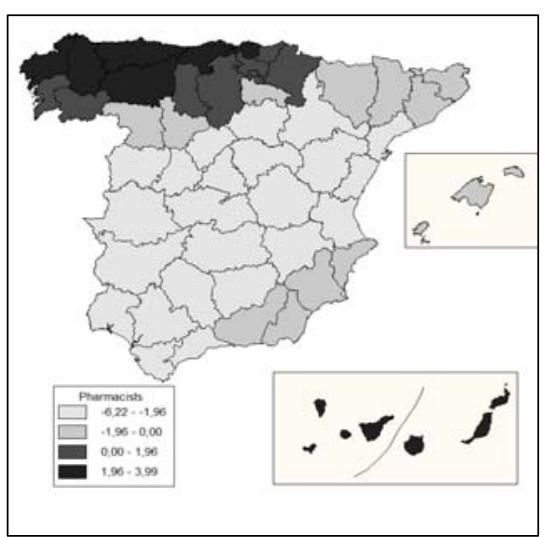

PHARM

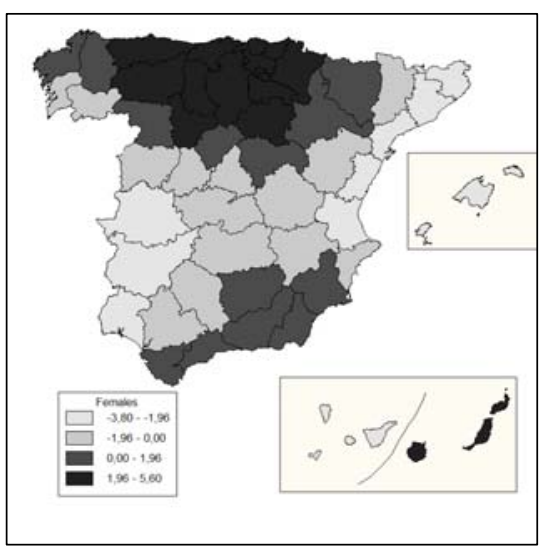

FEM

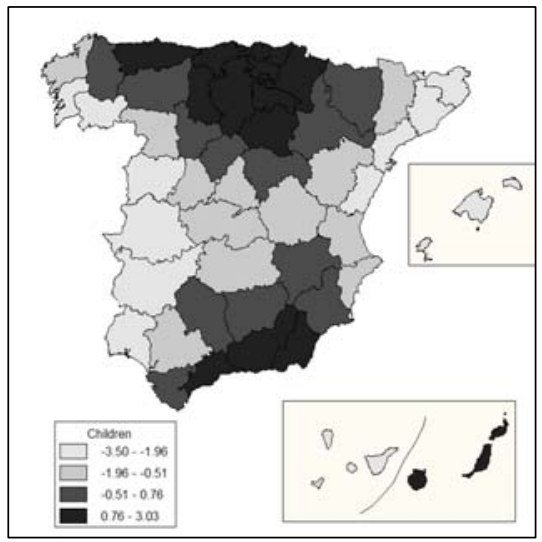

CHILD

(C) Southern Regional Science Association 2010. 
Figure 2 shows the distribution of variables (averaged over eight years) by province. Spatial patterns are predominant, though not of a unique nature. For the expenditure, a clear indication of spatial spillover is seen. Comparing the maps in Figure 2 to the map of ACs in Figure 1, this spillover seems to be of an intra- as well as a supra-AC nature. Further, there seems to be some tendencies to north/west-south/east contrasts. With respect to GDP, medical doctors, hospital beds, and to some extent, pharmacists, a clear north-south contrast is evident. This is also the case for some of the population characteristics, especially the population share of elderly, children, and to some extent females, while foreigners seem to cluster over the east coast provinces.

\section{RESULTS}

Models for public pharmaceutical expenditure were estimated using multiplicative CobbDouglas type specifications and linearized with log transforms of the explanatory variables. Two models - a baseline unexpanded model and another expanded by time and geographical coordinates-were estimated. To enhance interpretation, the geographical coordinates $H$ and $V$ were mean-adjusted prior to the estimations. All models control for residual temporal heterogeneity and dependency as well as spatial spillovers by applying an integrated SUR and SAC framework.

In both specifications, the estimated residual spatial autocorrelation parameter $(\lambda)$ is highly significant. This serves as a Wald test for spatial autocorrelation and indeed shows that the control for spatial autocorrelation is necessary. A comparison of the estimated spatial autocorrelation parameter of the two specifications further shows that the parameter is smaller for the expanded specification. Thus, while expansion may potentially induce spatial spillover, this seems not to be the case for the present investigation. Actually, the reduction in the magnitude of the spatial autocorrelation parameter when moving from the unexpanded to the expanded specification implies that some (although not all) spatial autocorrelation is handled via the expansion. Further, spatial autocorrelation persists throughout the period, as Moran tests calculated for all variables by year show substantial and persistent spatial autocorrelation in each (see Lauridsen et al., 2010).

Comparing the unexpanded specification (1) and the specification expanded by time (2), the importance of accounting for temporal parametric heterogeneity is evident. The LogL, AIC and $R^{2}$ criteria strongly support a preference for the expanded specification. Wald tests support both the full expansion as well as the temporal and geographical components. Further, one or more expansion coefficients are found to be significant for all variables. Several interpretational differences are obtained across the unexpanded and the expanded specifications. While the unexpanded specification reports GDP to be insignificant, the expanded specification shows that the coefficient of GDP varies considerably across geography. The significantly positive baseline coefficient refers to the case $T=H=V=0$ (i.e., the effect for 1995 for a province located in the geographical midpoint of Spain). This should not be directly compared to the corresponding coefficient of the unexpanded model (1). To support interpretation of the geographical pattern, Figure 3 shows the $t$-values of the coefficients by provinces (averaged over years). From the figure, it is seen that GDP-averaged across years-exerts a significantly positive impact on EXP in southern Spain, while a significantly negative impact is exerted in northwestern and northeastern Spain. This great variation in the effect of GDP across provinces potentially explains the statistical insignificance of the variable in the unexpanded specification. That is, the wide differences among the provinces cancel each other out so that the net effect for the 


\section{FIGURE 4. Coefficients by Year (averaged over provinces)}

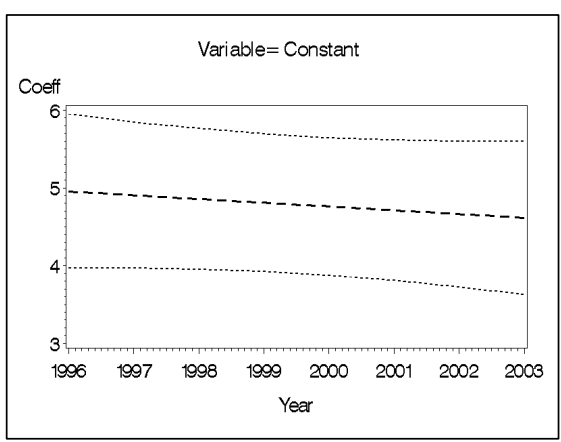

Constant

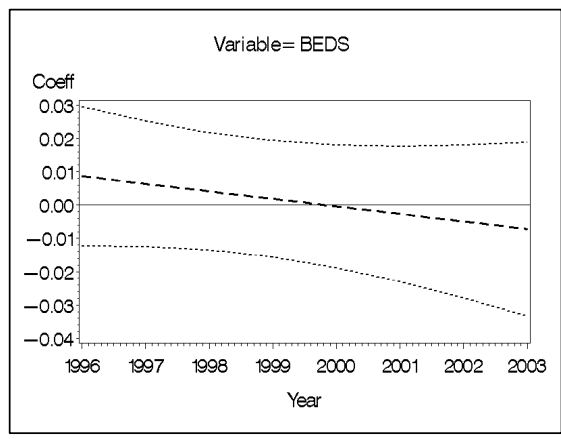

$B E D$

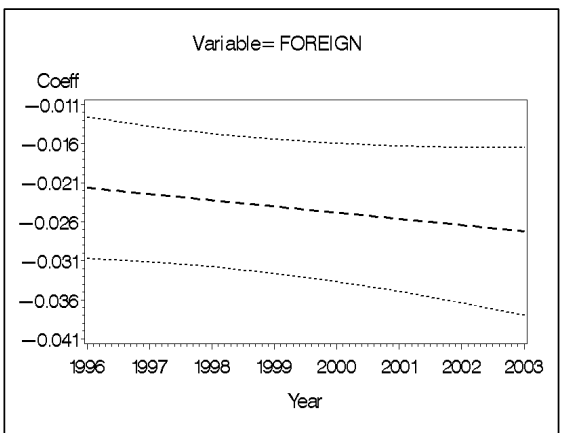

FOREIGN

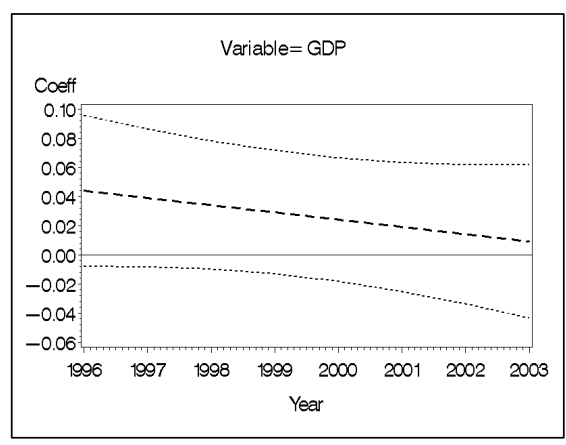

GDP

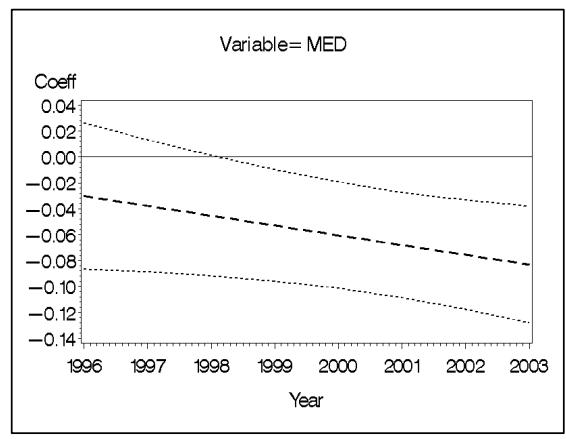

MED

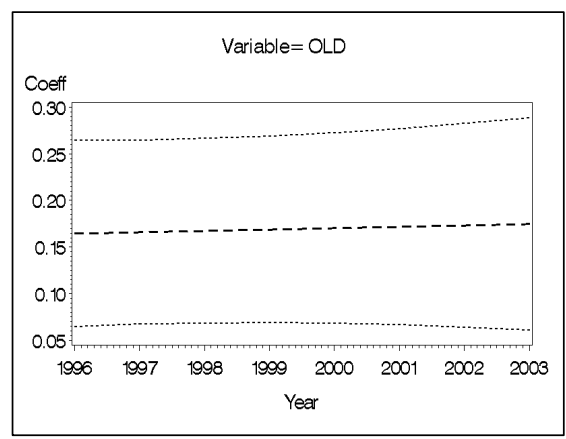

$O L D$

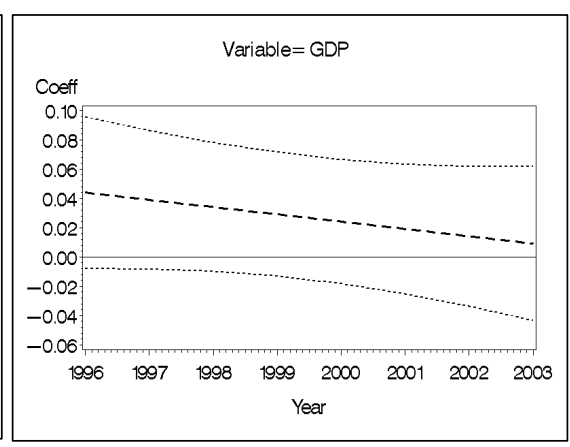

GDP

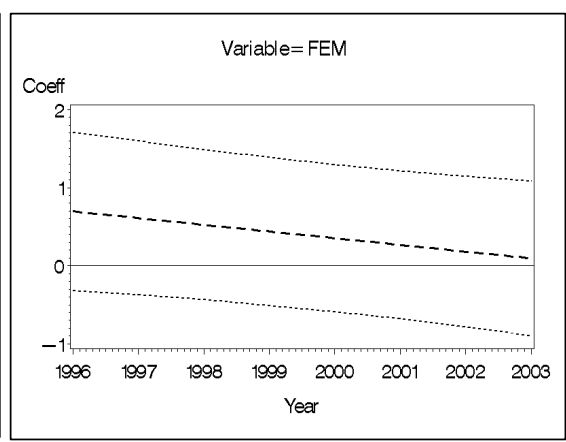

FEM

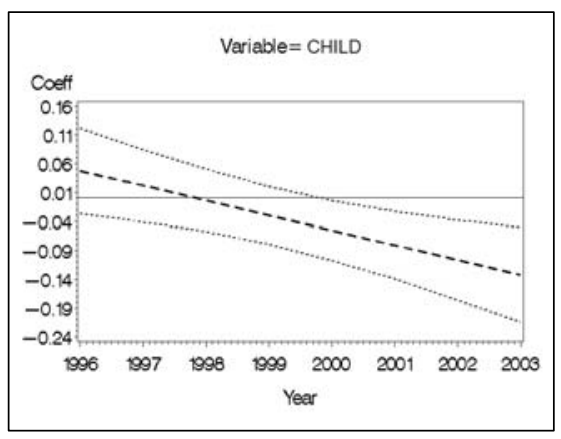

CHILD

"average" province is close to zero. This is confirmed in Figure 4, which shows that the "average" province in any year has a GDP effect with a confidence interval spanning zero.

Likewise, the coefficients for health system characteristics display considerable geographic variation. The average of the effect across years of PHARM on EXP is seen to be significantly negative in central Spain and significantly positive in the northwest. This contrasts with the unexpanded specification (1) of Table 2 where significant positive effects are reported, as well as from the evidence in Figure 4 that shows the effect for an "average" province is not statistically different from zero. Across years the average effect of BEDS varies from 
significantly negative in the southeast to significantly positive in a belt of northern provinces, except for the northwestern provinces in Galicia and Asturia. This evidence provides a modification of the results from the unexpanded specification of Table 2 which reports only a marginally significant effect confirmed by Figure 4, where the "average" province has an effect that is not significantly different from zero for any year. Regarding $M E D$, a significantly negative average effect across years is found for the northern provinces, while a significant positive effect is reported for the southern provinces, with the exception of a belt of provinces along the southeast coast. The effect of $M E D$ differs over time since the coefficient for the time interaction term is significant and negative. Consider Figure 4, where the coefficients are shown by years (averaged over provinces) together with 95 percent confidence intervals. The effect of $M E D$ drops from insignificant to significant, but negative, during the years.

TABLE 2. Seemingly Unrelated Regression Model of Pharmaceutical Expenditures

\begin{tabular}{|c|c|c|c|c|c|c|c|c|}
\hline & \multicolumn{3}{|l|}{ "Unexpanded } & \multicolumn{4}{|c|}{ "Time and space expanded } & \multirow[b]{2}{*}{$\alpha_{H V}$} \\
\hline & $\alpha_{0}$ & $\alpha_{0}$ & $\alpha_{T}$ & $\alpha_{H}$ & $\alpha_{H H}$ & $\alpha_{V}$ & $\alpha_{V V}$ & \\
\hline Constant & $\begin{array}{c}5.349 * * * \\
(0.546)\end{array}$ & $\begin{array}{c}3.945^{* * *} \\
(0.664)\end{array}$ & $\begin{array}{c}-0.048 \\
(0.065)\end{array}$ & $\begin{array}{c}0.190 \\
(0.202)\end{array}$ & $\begin{array}{c}-0.062 \\
(0.039)\end{array}$ & $\begin{array}{c}0.821^{* * *} \\
(0.227)\end{array}$ & $\begin{array}{c}0.276^{* * * *} \\
(0.083)\end{array}$ & $\begin{array}{c}-0.140 * \\
(0.075)\end{array}$ \\
\hline GDP & $\begin{array}{c}0.038 \\
(0.025)\end{array}$ & $\begin{array}{c}0.117 * * * \\
(0.032)\end{array}$ & $\begin{array}{l}-0.005 \\
(0.005)\end{array}$ & $\begin{array}{l}-0.010 \\
(0.007)\end{array}$ & $\begin{array}{c}-0.008^{* * *} \\
(0.002)\end{array}$ & $\begin{array}{c}-0.021 * * * \\
(0.008)\end{array}$ & $\begin{array}{c}0.001 \\
(0.003)\end{array}$ & $\begin{array}{c}0.006 * * \\
(0.002)\end{array}$ \\
\hline PHARM & $\begin{array}{c}0.097 * * * \\
(0.023)\end{array}$ & $\begin{array}{c}-0.132 * * * \\
(0.028)\end{array}$ & $\begin{array}{c}0.002 \\
(0.003)\end{array}$ & $\begin{array}{c}0.001 \\
(0.010)\end{array}$ & $\begin{array}{c}0.001 \\
(0.003)\end{array}$ & $\begin{array}{c}0.033^{* * *} \\
(0.010)\end{array}$ & $\begin{array}{c}0.016 * * * \\
(0.004)\end{array}$ & $\begin{array}{c}-0.009 * * \\
(0.004)\end{array}$ \\
\hline BEDS & $\begin{array}{l}0.014^{*} \\
(0.008)\end{array}$ & $\begin{array}{c}0.018 \\
(0.016)\end{array}$ & $\begin{array}{l}-0.002 \\
(0.002)\end{array}$ & $\begin{array}{c}-0.010^{* * *} \\
(0.003)\end{array}$ & $\begin{array}{c}0.001 \\
(0.001)\end{array}$ & $\begin{array}{c}0.021^{* * *} \\
(0.005)\end{array}$ & $\begin{array}{c}-0.006 * * * \\
(0.002)\end{array}$ & $\begin{array}{c}0.007 * * * \\
(0.002)\end{array}$ \\
\hline MED & $\begin{array}{c}0.002 \\
(0.023)\end{array}$ & $\begin{array}{c}0.088 * * * \\
(0.030)\end{array}$ & $\begin{array}{c}-0.008 * \\
(0.004)\end{array}$ & $\begin{array}{c}-0.025^{* * * *} \\
(0.008)\end{array}$ & $\begin{array}{l}0.005^{*} \\
(0.002)\end{array}$ & $\begin{array}{c}-0.053^{* * * *} \\
(0.009)\end{array}$ & $\begin{array}{c}-0.020 * * * \\
(0.004)\end{array}$ & $\begin{array}{c}0.004 \\
(0.004)\end{array}$ \\
\hline FEM & $\begin{array}{l}-0.147 \\
(0.535)\end{array}$ & $\begin{array}{c}0.130 \\
(0.694)\end{array}$ & $\begin{array}{c}-0.086 * \\
(0.050)\end{array}$ & $\begin{array}{l}0.365 * \\
(0.205)\end{array}$ & $\begin{array}{c}-0.224 * * * \\
(0.047)\end{array}$ & $\begin{array}{c}0.816^{* * *} \\
(0.241)\end{array}$ & $\begin{array}{c}0.438 * * * \\
(0.091)\end{array}$ & $\begin{array}{c}-0.104 \\
(0.080)\end{array}$ \\
\hline FOREIGN & $\begin{array}{l}-0.005 \\
(0.005)\end{array}$ & $\begin{array}{c}-0.016^{* * *} \\
(0.005)\end{array}$ & $\begin{array}{c}-0.001 \\
(0.001)\end{array}$ & $\begin{array}{c}0.004^{* * * *} \\
(0.001)\end{array}$ & $\begin{array}{l}-0.001^{*} \\
(0.0004)\end{array}$ & $\begin{array}{c}0.002 \\
(0.002)\end{array}$ & $\begin{array}{c}0.001 \\
(0.001)\end{array}$ & $\begin{array}{c}0.001 \\
(0.001)\end{array}$ \\
\hline OLD & $\begin{array}{c}0.131^{* * * *} \\
(0.048)\end{array}$ & $\begin{array}{c}0.164^{* * *} \\
(0.060)\end{array}$ & $\begin{array}{c}0.001 \\
(0.005)\end{array}$ & $\begin{array}{l}-0.011 \\
(0.020)\end{array}$ & $\begin{array}{l}0.007 * \\
(0.004)\end{array}$ & $\begin{array}{l}-0.004 \\
(0.027)\end{array}$ & $\begin{array}{l}-0.003 \\
(0.008)\end{array}$ & $\begin{array}{l}-0.010 \\
(0.008)\end{array}$ \\
\hline CHILD & $\begin{array}{c}-0.022 \\
(0.026)\end{array}$ & $\begin{array}{l}0.096 * \\
(0.051)\end{array}$ & $\begin{array}{c}-0.026 * * * \\
(0.009)\end{array}$ & $\begin{array}{l}0.021 * \\
(0.012)\end{array}$ & $\begin{array}{c}-0.013^{* * *} \\
(0.003)\end{array}$ & $\begin{array}{c}0.015 \\
(0.011)\end{array}$ & $\begin{array}{c}0.016^{* * *} \\
(0.005)\end{array}$ & $\begin{array}{c}-0.001 \\
(0.004)\end{array}$ \\
\hline$\lambda$ & $\begin{array}{c}0.906^{* * *} \\
(0.013)\end{array}$ & & & & $\begin{array}{c}0.758 * * * \\
(0.041)\end{array}$ & & & \\
\hline LogL & 1367.66 & & & & 1468.37 & & & \\
\hline AIC & -2643.32 & & & & -2736.74 & & & \\
\hline $\mathrm{R}^{2}$ & 0.125 & & & & 0.798 & & & \\
\hline Wald test & $108.40 * * *$ & & & & $93.02 * * *$ & & & \\
\hline Wald test & $201.42 * * *$ & & & & & & & \\
\hline
\end{tabular}


Socio-demographic variables exhibit temporal as well as geographical heterogeneity. The effect of FEM is, on average across years, significant and negative in provinces in eastern and western Spain (especially in Extremadura, Valenciana, and Cataluña) and both significant and positive in the Northern ACs. The effects erode over time as indicated by Figure 4 . This is different evidence than that from the unexpanded specification of Table 2, which reports the effect of FEM to be insignificant. The average effect of FOREIGN across provinces is negative but grows larger somewhat over time (Figure 4). Interestingly, the average trend in most of the country is significant and negative. The exception is the northeastern provinces which reveal no effect for FOREIGN. Again, this is different from the message of the unexpanded specification, which reports an insignificant effect. The average effect of $O L D$ across provinces is significant and positive over time. The average trend effect is likewise positive for most provinces; an exception is the very southern provinces and some northeastern ones, where it reveals no effect. These findings correspond well with the unexpanded specification, which reports a significant and positive effect. Finally, the average effect across provinces of CHILD falls from significant and positive to significant and negative over time. The average trend effect is significant and negative for a few eastern and western provinces, while it is significant and positive for a few northern provinces in the Pais Vasco and Navarra ACs. Again, this contrasts starkly with results from the unexpanded specification, which reported an insignificant effect.

To summarize, the unexpanded specification reports overall average effects that are insignificant for several essential variables (GDP, BEDS, MED, FEM, FOREIGN, and CHILD). The expanded specification, however, reveals that these overall averages mask substantial variation in the effects across time (the case for MED and CHILD) and, especially, across

Figure 5. Standardized Residuals by Provinces (averaged over eight years)

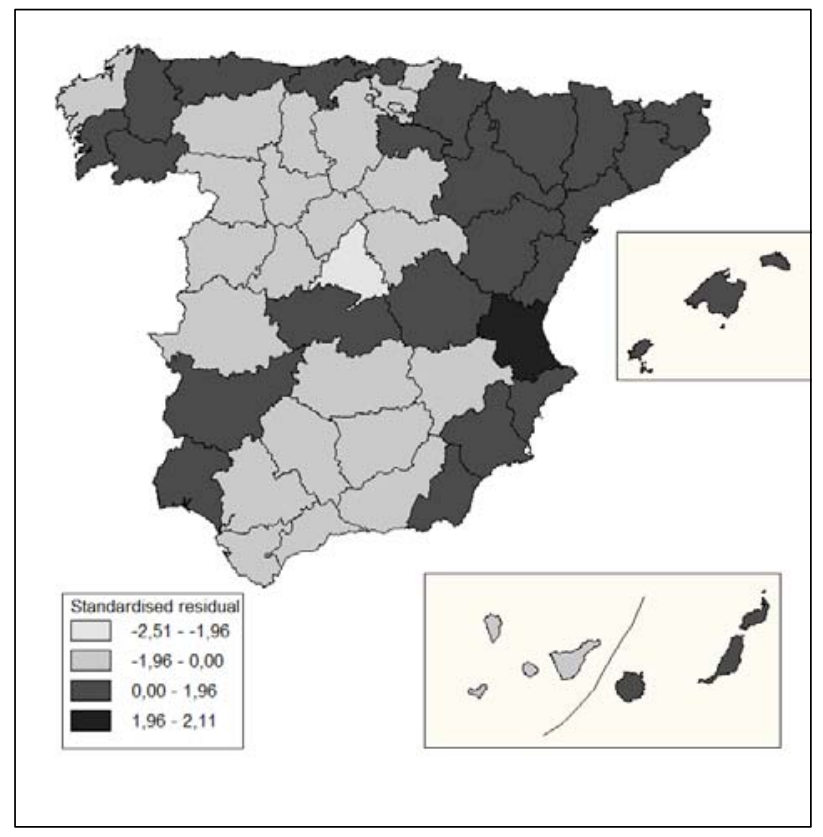


provinces (the case for all variables). While the overall average effect for a few variables (PHARM and $O L D$ ) is significant and positive, it masks substantial variation across provinces, spanning significant positive as well as significant negative effects.

Finally, Figure 5 shows the standardized residuals by provinces (averaged over years). The residuals for all but two provinces are within two standard deviations. Thus, spatial variation of the pharmaceutical expenditures seems to be captured well by the model. The standardized residuals were further inspected for normality using histograms, box plots, and indices of both skewness and kurtosis (not reported). This inspection did not reveal deviations from normality. Thus, the assumption of normality underlying the Maximum Likelihood estimation seems to be adequate.

\section{CONCLUSIONS}

The present study analyzes determinants of public pharmaceutical expenditure in Spain and adds to previous knowledge by explicitly modeling temporal as well as geographical parametric heterogeneity while controlling for unobserved residual patterns in the form of spatial spillover as well as temporal heterogeneity and interdependence. The necessity of accounting for the heterogeneous effects of determinants is evident, as the effects of all determinants are subject to substantial geographical and/or temporal variations. Especially, the effects of key determinants like GDP and health system characteristics are shown to be potentially misestimated when parametric heterogeneity is ignored. Thus, the complexity of spatial and temporal heterogeneity and spillover is clearly illustrated and the need for further evidence and development of modeling practice is demonstrated.

\section{REFERENCES}

Anselin, Luc. (1988) Spatial Econometrics: Methods and Models. Kluwer Academic Publishers: Amsterdam.

Casetti, Emilio. (1997) "The Expansion Method, Mathematical Modeling, and Spatial Econometrics,” International Regional Science Review, 20, 9-33.

Costa-Font, Joan and Jaume Puig-Junoy. (2004) "Regulatory Ambivalence and the Limitations of Pharmaceutical Policy in Spain,” Faculty of Economics and Business Working Paper 762: Universitat Pompeu Fabra.

Darbá, Josep. (2003a) "Pharmaceutical Expenditure and Therapeutic Value of New Medicines in Spain,” Pharmacoeconomics, 21, 1211-1212.

. (2003b) "Pharmaceutical Expenditure in Spain: Evolution and Cost Containment Measures during 1998-2001,” European Journal of Health Economics, 4, 151-157.

Dubois, Robert W., Anita J. Chawla, Cheryl A. Neslusan, Mark W. Smith, and Sally Wade. (2000) “Explaining Drug Spending Trends: Does Perception Match Reality?” Health Affairs, 19, 231-239.

Dubois, Robert W., Elaine Batchlor, and Sally Wade. (2002) "Geographic Variation in the Use of Medications: Is Uniformity Good News or Bad?” Health Affairs, 21, 240-250.

Ess, Silvia M., Sebastian Schneeweiss, and Thomas D. Szucs. (2003) "European Healthcare Policies for Controlling Drug Expenditure,” Pharmacoeconomics, 21, 89-103. 
Folland, Sherman, Allan C. Goodman, and Miron Stano. (2003) The Economics of Health and Health Care. Prentice Hall: Upper Saddle River, New Jersey.

Gerdtham, Ulf-G. and Douglas Lundin. (2004) "Why Did Drug Spending Increase during the 1990s? A Decomposition Based on Swedish Data,” Pharmacoeconomics, 22, 29-42.

Ham, Chris. (1988) “Health Care Variation: Assessing the Evidence,” King's Fund Institute Working Paper: London.

Joines, Jerry D., Irva Hertz-Picciotto I, Timothy S. Carey, Wilbert Gesler, and Chirayath Suchindran. (2003) "A Spatial Analysis of County-level Variation in Hospitalization Rates for Low Back Problems in North Carolina,” Social Science and Medicine, 56, 2541-2553.

Jones, John-P. and Emilio Casetti. (1992) Applications of the Expansion Method. Routledge: London.

Kitchener, Martin, Helen Carrillo, and Charlene Harrington. (2003) "Medicaid CommunityBased Programs: A Longitudinal Analysis of State Variation in Expenditures and Utilization,” Inquiry, 4, 375-389.

Lauridsen, Jørgen, Mickael Bech, Fernando López, and Mariluz Sánchez. (2010) “A Spatiotemporal Analysis of Public Pharmaceutical Expenditure,” Annals of Regional Science, forthcoming.

Levaggi, Rosella and Roberto Zanola. (2003) "Flypaper Effect and Sluggishness: Evidence from Regional Health Expenditure in Italy,” International Tax and Public Finance, 10, 535547.

Lopez-Casasnovas, Guillem. (2005) "Economic Considerations Regarding Pharmaceutical Expenditure in Spain and its Financing,” in Jaume Puig-Junoy, ed., The Public Financing of Pharmaceuticals: An Economic Approach. Edward Elgar: Cheltenham, pp. 189-208.

Lopez-Casasnovas, Guillem, Joan Costa-Font, and Ivan Planas. (2005) "Diversity and Regional Inequalities in the Spanish System of Health Care Services,” Health Economics, 14, S221-235.

Lopez-Casasnovas, Guillem and Marc Saez. (2001) "A Multilevel Analysis on the Determinants of Regional Health Care Expenditure: A Note,” Research Centre on Health and Economics Working Paper 572.

Metge, Colleen, Charlyn Black, Sandra Peterson, and Anita L. Kozyrskyj. (1999) “The Population's Use of Pharmaceuticals,” Medical Care, 37, JS42-59.

Morgan, Steven G. (2005) "Booming Prescription Drug Expenditure-A Population-Based Analysis of Age Dynamics,” Medical Care, 43, 996-1008.

Moscone, Francesco and Martin Knapp. (2005) "Exploring the Spatial Pattern of Mental Health Expenditure,” Journal of Mental Health Policy and Economics, 8, 205-217.

Puig-Junoy, Jaume. (2004) “Incentives and Pharmaceutical Reimbursement Reforms in Spain,” Health Policy, 67, 149-165.

Rovira, Joan, Ramon Tremosa, Antoni Gilabert, and Miquel Torralba. (2001) "The Role of Prices in Drug Expenditure Analysis,” Health Economics in Prevention and Care, 2, 142-149. 
Wennberg, John E. and Alan Gittelsohn. (1973) "Small Area Variation in Health-Care Delivery,” Science, 182, 1102-1107.

Westert, Gert P., Peter P. Groenewegen, Hendriek C. Boshuizen, Peter M. M. Spreeuwenberg, and Martin P.M. Steultjens. (2004) "Medical Practice Variations in Hospital Care; Time Trends of a Spatial Phenomenon," Health \& Place, 10, 215-220.

Zellner, Arnold. (1962) "An Efficient Method of Estimating Seemingly Unrelated Regressions and Tests of Aggregation Bias," Journal of the American Statistical Association, 57, 348-368. 